\title{
The mechanism design of the main body of electricity retailing
}

\author{
Weiwei Yuan ${ }^{1, \text { a }}$ and Dezhi Li ${ }^{2, b}$ \\ ${ }^{1}$ North China Electric Power University, Beijing, 102206, China; \\ ${ }^{2}$ China Electric Power Research institute, Beijing, 100192, China. \\ a1712676903@qq.com, bldz97@126.com
}

Keywords: mechanism design, main body of electricity retailing, electricity market.

\begin{abstract}
This paper introduces the mechanism design of the main body of electricity retailing. Under the background of new electric retailing reform, it is of great significance and necessity to study the new mechanism which is adapted to the increasingly fierce competition in the electric market.
\end{abstract}

\section{Introduction}

Since the 1980s, the reform of electricity market in order to 'break the monopoly and introducing competition' got fast development in Britain, the United States,

Australia, Northern Europe and other countries or regions [1]. Last round of electric power system reform in our country began on February 10,2002 promulgated by the state council of the electric power system reform plan ([2002] No.5). After that, our country has basically formed competition situation in power generation side ${ }^{[2]}$. However, there are still many prominent contradictions and deep-seated problems in the development of electric power industry. Thus, the state council issued 'the opinions on further deepening the reform of the electric power system'(found [2015] 9) on March 15,2015 , which marked the official start of the new round of reform of electricity market[3].

The main body of electricity retailing is the units or individuals that have achieved power class electric power business license (electric power business license referred to the power generation,transmission and the power supply business.) ,power supply business permit (power supply business permit license), in accordance with the law to carry out the placement of the electricity business units or individuals. We should know that it is necessary to have a combination of the electric power business license, the power supply business permit certificate before the placement of the electricity business ${ }^{[4]}$.

\section{Mechanism design}

\subsection{Business model}

\subsubsection{Basic electricity retailing model}

Electric power marketing service is the foothold of the electricity retailing company and the basis for the starting business with the users.In the operating mode, electricity retailing company can use the data to master a lot of areas, for power generation companies, power grid company, distribution company to carry out the load forecasting, assisted in the economic operation of power system. At the same time, electricity retailing company can assist in the management in the demanded side, which demand intention reflect in the price or contract directly. For large commercial and industrial users, the most complicated contract of power trading, the highest quality of the power requirements, so electricity retailing companies provide services such as contract management and power quality analysis.

\subsubsection{Additional value-added service mode}

Electricity retailing company will be service-oriented businesses in the future,in addition to the labor of the retail of electricity business. There are differences that should be undertaken according to their own characteristics and advantages of value-added services, to meet the needs of different types of users. 
Electricity retailing company may, according to the demand of the industrial and commercial enterprises and other large users, develop electricity management services, as its historical loading data, analysis of energy consumption level, formulate reasonable electricity scheme. Second, electricity retailing company should provide equipment and the overall energy analysis to help save electricity costs according to the electricity usage of medium-sized users and small home users. At the same time, sell electricity company can draw lessons from Germany Emprimo sales experience, according to the user's special requirements tailored for the user the power package. In addition, electricity retailing company can use monitored research platform and energy monitoring service to track the effect of personalized solutions.

\subsection{Profit model}

\subsubsection{Basic mode}

The profit model of electricity retailing company is the basis of using the information asymmetry between power generation side and user side,the use of current domestic surplus thermal power capacity,earn price difference greater bargaining power.If sell electricity company relying only on basic mode,as more capital into the market,this kind of sell electricity company will gradually eliminated by the market.Current into the electric power market sell electricity companies are in the stage of this model.

\subsubsection{Advanced mode}

The electricity retailing company can also provide power, heating, heating and gas supply as well as they can provide comprehensive energy services ${ }^{[2]}$. This type of electricity retailing company can design different comprehensive energy service plans, make their profits hidden in the comprehensive service.This behavior make the consumers feel gained already, and also make such electricity retailing company 's profits increase greatly.

\subsubsection{The ultimate mode}

This type of electricity retailing company often take method to implement real-time prices and the risk will be passed on to consumers to make fixed spreads.

\subsection{The marketing strategy}

\subsubsection{Form a complete product combination}

Considering the characteristics of power products that is basically no quality difference, so in full guarantee to provide high quality power, on the basis of core products, namely focused on the product in the form of a layer and extension layer. First,provide users with value-added services for the purpose of market sharing increased,such as providing demand's side management services to enterprise consultants or transform the designer's identity to the user of energy conservation

Second, under the condition of positive research in national policy allows, provide the peak valley, time-sharing electricity product portfolio for the user to choose from; The third is the conditional enterprises implement the user's heat, electricity, and form a close bond; The fourth is to select the appropriate power generation or sell electricity main body to form product security alliance, as a reserve force of its own power supply,ensure the continuous and stable power supply to the user.

\subsubsection{Formulate scientific pricing strategy}

Build market trading price decision-making system,the establishment of different boundary conditions on the price of lower limit calculation module,study to determine the power plant under different working hours, different price curve,form offer rapid response ability.Not profitable to sell electricity company, the power generation company spreads the basis of direct transmission, in terms of pricing strategy mainly consider the following several aspects:one is the research of electricity price linkage with users, the formation of long-term cooperation of price alliance;Second,according to the competition demand formulate trade for a long period of time difference between users and short cycle trading pricing strategy; Three is the study of electricity industry and product,on the basis of product on electricity price sensitivity difference according to the electricity pricing;Fourth, based on micro electric power market supply and demand of tracking, cycle points for quotation;Five is provided by the peak valley,time-sharing product portfolio,such as providing perfect price. 


\subsubsection{Build strong retailing channels}

On the management mode, in the provincial company, on the basis of unified management,and implementing the company's total score management allows sell electricity company in a power plant, relying on geographical advantages and the local political advantage to consolidate and expand market share. To arouse the enthusiasm of the power plant,and allow the power plant across regions to expand the market,even with the company business scope overlap.Consideration,from the Angle of reasonable layout can be established with power companies holding, local state-owned assets,industrial park, or users to take a stake in joint venture sell electricity company, drive sell electricity company promoted by asset bond politics, public relations, advantages, and strengthen the market share; Prospect of development potential, the product is good for industry users, can consider to cooperation form sell electricity company;Forward considering selling electricity company covers all of industrial park and high quality customer,in the case of stationing has not yet been implemented in recent,can consider through cooperation with insurance companies and other types of enterprises, realizing a complete coverage of the user's work, to make up for sell electricity companies to form initial stage to the problem of shortage of staff.

\section{Summary}

(1) Foster the main body of electricity retailing adopting the combination of regulation and market-oriented method. According to the number of new sell electricity subject and market share, gradually decrease and eventually cancelled the traditional sell electricity price controls, eventually become the main body diversity, share balance, business practices, open and flexible, fully competitive electricity sales market.

(2) Strengthen the user's side adopting the Internet. Electricity retailing reform's ultimate goal is to become the optimization allocation of power resources, power sales market and sell electricity is the nature of power sales market main body.

(3) Reduce the risk of the users. Trying to enter the power sales market and different subjects from selling electricity at least five channels, its financial status, technical level, target users may be different, it is difficult to formulate unified access standards.

(4) Response to electricity demand in hosting state. To ensure the safety of the users of electricity power regulator is recommended to establish public welfare to sell electricity, in hosted mode service in a short period of time can't sign the new sale electricity or for some reason fail to choose to sell electricity power users.

\section{References}

[1] Zeng Ming,Zhou Jian,Yu Ying.Foreign electricity reform enlightenment on retail electricity market construction in our country [J].Reform and the strategic,2009,25(4):179-182.

[2]Du Songhuai,Wen Buying,Jiang jing.The power market [M]. Beijing:China electric power press, 2008: 53-56.

[3]SUN Jinwen, WAN Yunfei, ZHENG Peiwen, et al. Coordinated charging and discharging strategy for electric vehicles based on demand side management [J]. Transactions of China Electrotechnical Society, 2014,29(8): 64-69.

[4] Ofuji K,Tatsumi N.Wholesale and retail electricity markets in Japan:Results of market revitalization measures and prospects for the current reform [J]. Economics of Energy \& Environmental Policy, 2016, 5(1): 31-49. 